\title{
PENINGKATAN KUALITAS DAN KUANTITAS SUMBERDAYA MANUSIA \\ PADA KESATUAN PENGELOLAAN HUTAN LINDUNG (KPHL) BATUTEGI DAN KOTA AGUNG UTARA DI PROVINSI LAMPUNG
}

\section{(IMPROVED QUALITY AND QUANTITY OF HUMAN RESOURCES IN PROTECTED FOREST MANAGEMENT UNIT (KPHL) BATUTEGI AND KOTA AGUNG UTARA OF LAMPUNG PROVINCE)}

\author{
Siti Rohana, Christine Wulandari, dan Slamet Budi Yuwono \\ Jurusan Kehutanan Fakultas Pertanian Universitas Lampung \\ Jln. Prof. Dr. Soemantri Brojonegoro No. 1 Gedung Meneng Bandar Lampung \\ Email : rohanasiti583@yahoo.com \\ Nomor telepon : 082379068074
}

\begin{abstract}
ABSTRAK
Pengelolaan hutan secara lestari bertujuan untuk memperoleh manfaat sebesar-besarnya untuk kemakmuran rakyat. Dalam mewujudkan hutan lestari, pengelolaan KPHL harus memperhatikan sumberdaya manusia (SDM) pengelolanya. Tujuan penelitian yang dilaksanakan pada bulan Mei-Juni 2014 adalah memetakan kualitas dan kuantitas SDM di KPHL Batutegi dan KPHL Kota Agung Utara di Provinsi Lampung serta menyusun rekomendasi upaya peningkatan kualitas dan kuantitas SDM yang diperlukan oleh KPHL. Data dikumpulkan melalui pengamatan langsung di lapangan, wawancara dan dianalisis secara kuantitatif dan deskriptif. Hasil penelitian dari aspek kualitas, SDM di KPHL Batutegi yang berkualitas sebesar 39\% dan kurang berkualitas sebesar $61 \%$ serta SDM di KPHL Kota Agung Utara yang berkualitas $42 \%$ dan kurang berkualitas 58\%. Peningkatan kuantitas SDM yang diperlukan untuk KPHL Batutegi adalah 4 SDM jabatan fungsional umum dan 53 SDM jabatan fungsional tertentu, sedangkan untuk KPHL Kota agung Utara diperlukan 16 SDM jabatan fungsional umum dan 99 SDM untuk jabatan fungsional tertentu.
\end{abstract}

Kata kunci: kualitas, kuantitas, sumberdaya manusia, KPHL

\section{ABSTRACT}

Sustainable forest management aims to benefit maximum for the prosperity of the people. Achieving sustainable forest management, KPHL should pay attention to human resources (HR) managers. The purpose of the research was carried out in May-June 2014 is charting the quality and quantity of human resources in KPHL Batutegi and KPHL Kota agung Utara in the province of Lampung and drawing up recommendations for efforts to improve the quality and quantity of human resources needed by the KPHL. Data collected by direct observation in the field, interviews and analyzed quantitative and descriptive. Research results from the aspect of quality of human resources in KPHL Batutegi, of 39\% has good quality and $61 \%$ of less quality as well as human resources in the KPHL Kota Agung Utara qualified $42 \%$ and less qualified $58 \%$. The increase in the quantity human resources required 4 staff KPHL Batutegi general functional and 53 human resources functional position, while for KPHL Kota Agung Utara 16 staff of general functional human resources and 99 staff for certain functional position.

Keywords: quantity, quality, human resources, KPHL 


\section{PENDAHULUAN}

\section{Latar Belakang}

Penguasaan hutan oleh negara memberi wewenang kepada Pemerintah untuk mengatur dan mengurus segala sesuatu yang berkaitan dengan hutan, kawasan hutan dan hasil hutan dengan tujuan untuk memperoleh manfaat sebesar-besarnya serta serba guna dan lestari untuk kemakmuran rakyat melalui kegiatan yang salah satunya adalah pengelolaan hutan (UndangUndang No. 41 tahun 1999). Dibutuhkan suatu penyelenggaraan pengelolaan hutan di tingkat tapak, melalui pembentukan unit pengelolaan hutan atau Kesatuan Pengelolaan Hutan atau KPH (Lestari, et al, 2012).

Berdasarkan Pasal 28 ayat (2) PP No. 44 Tahun 2004 tentang Perencanaan Kehutanan, unit pengelolaan hutan terdiri dari Kesatuan Pengelolaan Hutan Konservasi (KPHK), Kesatuan Pengelolaan Hutan Lindung (KPHL) dan Kesatuan Pengelolaan Hutan Produksi (KPHP). Penetapan wilayah KPHL Provinsi Lampung oleh Menteri Kehutanan melalui SK Menhut Nomor K.68/Menhut-II/2010 tanggal 28 Januari 2010 meliputi area seluas \pm 518.913 ha terdiri dari 9 unit KPHL seluas \pm 277.690 ha dan 7 unit Kesatuan Pengelolaan Hutan Produksi (KPHP) seluas \pm 241.223 ha. Dari 9 unit KPHL 4 unit sebagai model KPHL, yaitu KPHL Model Gunung Rajabasa, KPHL Model Batutegi, KPHL Model Kota Agung Utara dan KPHL Pesawaran.

Pengelolaan KPHL yang berjalan sejak ditetapkannya P.6/MENHUT-II/2010 (tentang norma, standar, prosedur dan kriteria pengelolaan hutan pada KPHL dan KPHP). Pengelolaan KPHL di Lampung sudah berjalan lima tahun dan belum banyak informasi mengenai kualitas dan kuantitas SDM, sehingga dilakukan penelitian tentang pemetaan sumberdaya manusia yang bertujuan untuk mengetahui kualitas dan kuantitas sumberdaya manusia yang diharapkan dimiliki dalam organisasi KPHL.

\section{Tujuan penelitian}

Mengetahui kualitas dan kuantitas Sumber Daya Manusia (SDM) di KPHL Batutegi dan KPHL Kota Agung Utara di Provinsi Lampung serta menyusun rekomendasi upaya peningkatan kualitas dan kuantitas SDM yang diperlukan oleh KPHL

\section{METODE PENELITIAN}

\section{Waktu dan Tempat}

Penelitian dilaksanakan selama bulan Mei 2014 di KPHL Batutegi dan KPHL kota Agung Utara.

\section{Alat dan Objek Penelitian}

Alat yang digunakan dalam penelitian ini adalah kamera, kuisioner, laptop dan alat tulis. Sedangkan objek penelitian ini adalah pegawai di KPHL Batu Tegi dan KPHL Kota Agung Utara, masyarakat sekitar KPHL dan Lembaga Swadaya Masyarakat.

\section{Definisi Operasional}

Batasan operasional penelitian ini adalah

a. Kategori berkualitas adalah jumlah persentase SDM kategori sangat mampu dan mampu dalam bidang perencanaan hutan dan pengelolaan DAS dan perhutanan sosial.

b. Kategori kurang berkualitas adalah jumlah persentase SDM kategori kurang mampu dan tidak mampu dalam bidang perencanaan hutan dan pengelolaan DAS dan perhutanan sosial.

c. Kategori setuju adalah jumlah persentase kategori SDM sangat setuju dan setuju tentang dibentuknya KPHL. 
d. Kategori kurang setuju adalah jumlah persentase SDM kategori kurang setuju dan tidak setuju tentang dibentuknya KPHL.

\section{Metode Penelitian \\ Jenis Data}

Jenis data yang digunakan dalam penelitian ini adalah data primer dan data sekunder. Data primer adalah data yang diperoleh langsung dari sumbernya meliputi kualifikasi, jumlah, dan potensi pegawai KPHL. Data sekunder merupakan data penunjang penelitian. Data ini meliputi luas KPHL, Standar Operasional Prosedur (SOP), tata batas KPHL, struktur organisasi, potensi konflik serta referensi penunjang yang berkaitan dengan penelitian yang bersumber dari pustaka ataupun instansi terkait.

\section{Cara pengumpulan data}

Metode pengumpulan data dilakukan dengan cara:

1. Wawancara dengan responden

Wawancara dilakaukan pada pegawai KPHL, masyarakat yang berbatasan langsung dengan KPHL serta Lembaga Swadaya Masyarakat (LSM) yang bekerja sama dengan pihak KPHL.

2. Studi pustaka

Data penunjang data primer untuk mendapatkan gambaran secara umum.

\section{Responden Penelitian}

Populasi dalam penelitian ini adalah SDM di KPHL Batu Tegi sebanyak 20 orang, SDM di KPHL Kota Agung Utara sebanyak 23 orang. Menurut Arikunto (2011), jika jumlah populasi kurang dari 100 orang, maka digunakan metode sensus yaitu sampel yang digunakan untuk penelitian adalah seluruh populasi. Untuk pengambilan sampel masyarakat sekitar digunakan sampling purposif (bertujuan) yang menurut Sudjarwo dan Basrowi (2009) merupakan cara atau teknik pengambilan sampel yang ditetapkan secara sengaja oleh peneliti atas dasar kriteria atau pertimbangan tertentu dengan tujuan tertentu. Sampel LSM adalah total dari LSM yang ada di sekitar lokasi penelitian untuk KPHL Batutegi sebanyak 7 SDM dan 10 SDM untuk KPHL Kota Agung Utara. Jumlah sampel masyarakat sekitar KPHL Batutegi dan Kota Agung Utara 10 orang yang merupakan ketua gabungan kelompok tani (GAPOKTAN) yang dianggap mewakili pendapat dari masing-masing anggota.

\section{Analisis Data}

Data yang diperoleh diolah dengan sistem tabulasi dan analisis data dilakukan secara kuantitatif dan deskriptif dan disajikan dalam bentuk tabel dan grafik. Pengolahan data bertujuan mengubah data mentah dari hasil pengukuran menjadi data yang lebih halus sehingga memberikan arah untuk pengkajian lebih lanjut (Sudjana, 2001). Menurut Hasan (2006), tabulasi adalah pembuatan tabel-tabel yang berisi data yang telah diberi kode sesuai dengan analisis yang dibutuhkan.

\section{HASIL DAN PEMBAHASAN}

\section{A. Sumberdaya Manusia}

1. Kualitas Sumberdaya Manusia Bidang Perencanaan Hutan dan Pengelolaan DAS dan Perhutanan Sosial

Kemampuan Sumberdaya Manusia (SDM) di KPHL Batutegi dan KPHL Kota Agung Utara dibidang perencanaan hutan dan pengeloaan DAS dapat dilihat lebih rinci dapat dilihat pada Tabel 5. Sebagai ilustrasi potensi SDM bidang perencanaan hutan disajikan pada Gambar 1. 


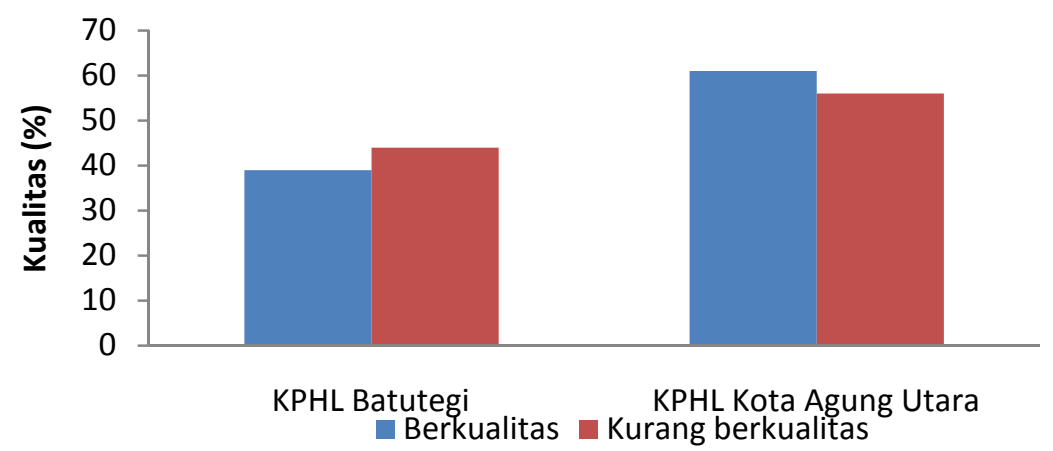

Gambar 1. Ketersediaan SDM bidang perencanaan hutan (\%)

Sumberdaya manusia KPHL Kota Agung Utara lebih berkualitas dibandingkan SDM KPHL Batutegi, karena secara umum tingkat pendidikan SDM lebih tinggi. Pada SDM KPHL Kota Agung Utara pendidikan tertinggi yakni strata 2 dan SDM KPHL Batutegi pendidikan teringgi yakni strata, secara rinci dapat dilihat pada Tabel 8. Kualitas Sumber Daya Manusia (SDM) terbukti menjadi faktor detenninan bagi keberhasilan pembangunan dan kemajuan suatu bangsa. Pengalaman negara-negara Asia seperti Jepang, Korea Selatan, Taiwan, Hongkong dan Singapura membuktikan kebanaran hal tersebut (Hidayat Syarief, 1998). Upaya membangun kualitas SDM tidak terlepas dari mutu pendidikan. Hal ini sesuai dengan pendapat Widianti (2007) bahwa seseorang yang berpendidikan lebih tinggi akan mempunyai pengetahuan yang lebih luas dibanding dengan seseorang yang tingkat pendidikannya rendah. Menurut Elfina (2007) tingkat pendidikan yang lebih tinggi dapat menunjang karyawan dalam meningkatkan kualitas kerja.

Tabel 5. Kualitas SDM bidang perencanaan hutan (\%).

\begin{tabular}{llrrrrr}
\hline \multirow{2}{*}{ No } & \multirow{2}{*}{ KPHL } & \multicolumn{4}{c}{ Kualitas } \\
\cline { 3 - 6 } & & 0 & \multicolumn{2}{c}{ Bekualitas } & \multicolumn{2}{c}{ Kurang Berkualitas } \\
\cline { 3 - 6 } & & Satutegi & 15 & 29 & 19 & Karang Mampu \\
\hline 1. & Kota Agung Utara & 15 & 11 & 44,8 \\
\hline
\end{tabular}

Sumber: Data Primer, 2014

Kemampuan di bidang pengelolaan DAS dan Perhutanan Sosial SDM di KPHL Batutegi yang berpotensi sebesar 39\% dan KPHL Kota Agung Utara sebesar 40\%, sedangkan SDM yang kurang berpotensi untuk KPHL Batutegi sebesar $61 \%$ dan untuk KPHL Kota Agung Utara $60 \%$ secara rinci dapat dilihat pada Tabel 2. Sebagai ilustrasi potensi SDM bidang perencanaan hutan disajikan pada gambar 2. Kemampuan berbagai bidang perlu dikuasai oleh para pegawai karena berhubungan erat dengan kegiatan pengelolaan hutan secara lestari di lapangan, seperti di dalam P.24/Menhut-II/2011 salah satu kualifikasi pegawai yaitu yang mempunyai kemampuan teknis dibidang kehutanan.

Menurut Suratno (2012) Keterbelakangan suatu organisasi pada umumnya dilatarbelakangi oleh minimnya kemampuan sumber daya manusia yang terlibat didalamnya, baik aspek manajerial maupun pada aspek operasional. Tuntutan upaya peningkatan kemampuan sumber daya manusia sangat mutlak untuk menciptakan organisasi yang lebih baik dan mengelolanya dengan tingkat efisiensi dan efektivitas yang tinggi sebagai wahana untuk mencapai berbagai tujuan yang ingin dicapai. Tingkat kualitas SDM dibidang perencanaan dan pengeloaan DAS dan perhutanan sosial KPHL Kota Agung Utara memiliki persentase lebih tinggi selain disebabkan tingkat pendidikan yang lebih tinggi 
juga dipengaruhi pelatihan yang diikuti oleh pegawai KPHL serta jumlah SDM yang lebih banyak. KPHL Batutegi memiliki 20 orang pegawai dan KPHL Kota Agung Utara berjumlah 23 orang pegawai. Menurut Badan Penelitan dan Pengembangan Kehutanan (2014) kecukupan sumberdaya manusia di KPHL sangat baik jika jumlah pegawai lebih dari 20 orang, dan dikatakan kecukupan sumberdaya manusia baik jika berjumlah 6-20 orang, jika berjumlah 1-5 dikatakan kurang baik.

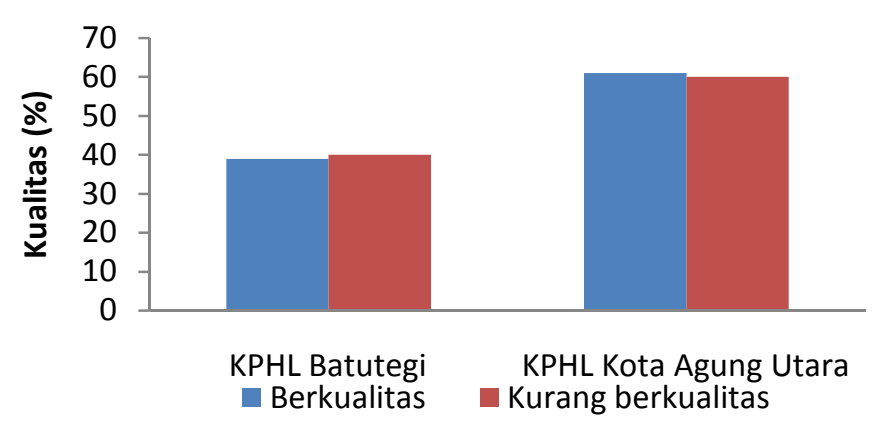

Gambar 4. Kualitas SDM bidang pengelolaan DAS dan perhutanan sosial (\%)

Jumlah sumber daya manusia yang besar apabila dapat didayagunakan secara efektif dan efisien akan bermanfaat untuk menunjang pengelolaan hutan secara efisien dan lestari.

Tabel 6. Kualitas SDM bidang pengelolaan DAS dan perhutanan sosial (\%).

\begin{tabular}{llrrrrr}
\hline \multirow{2}{*}{ No } & \multirow{2}{*}{ KPHL } & \multicolumn{4}{c}{ Kualitas } \\
\cline { 3 - 7 } & & \multicolumn{3}{c}{ Berkualitas } & \multicolumn{2}{c}{ Kurang berkualitas } \\
\cline { 3 - 7 } & & Sangat Mampu & Mampu & Kurang mampu & Tidak mampu \\
\hline 1. & Batutegi & 39 & 19 & 42 \\
2. & Kota Agung Utara & 12 & 28 & 13,5 & 46,5 \\
\hline
\end{tabular}

Sumber: Data Primer Diolah, 2014

\section{Kuantitaas SDM di KPHL Batutegi dan Kota Agung Utara}

Perencanaan sumberdaya manusia memberikan perkiraan tentang jumlah dan jenis karyawan yang diperlukan suatu organisasi untuk mencapai tujuan organisasi. Jumlah dan jenis karyawan yang dibutuhkan mempunyai pengaruh yang besar tujuan perencanaan SDM pada sebuah organisasi. Meskipun menurut Abdul (2008) Kuantitas menyangkut jumlah sumberdaya manusia kurang penting kontribusinya dalam pembangunan, dibandingkan dengan aspek kualitas. Bahkan kuantitas sumberdaya manusia tanpa disertai dengan kualitas yang baik akan menjadi beban pembangunan suatu bangsa. Sedangkan kualitas menyangkut mutu sumberdaya manusia tersebut, yang menyangkut kemampuan nonfisik (kecerdasan dan mental). Oleh sebab itu, untuk kepentingan percepatan suatu pembangunan di bidang apapun, maka peningkatan kualitas sumber daya manusia merupakan suatu persyaratan utama. Walaupun demikian untuk pengelolaan kawasan suatu KPH dibutuhkan SDM yan jumlahnya tidak sedikit agar tujuan pengelolaan tersebut tercapai, sehingga menurut Fathoni (2014) ada krtiteria pemenuhan SDM, yaitu: jumlah SDM saat ini, jumlah kegiatan teknis kehutanan (dalam Rencana Pengelolaan Hutan Jangka Panjang), dan luas hutan wilayah tertentu sehingga terpetakan jumlah SDM yang ideal untuk mengelola KPHL (Tabel 7). 
Tabel 7. Kuantitas SDM di KPHL Batutegi dan Kota Agung Utara.

\begin{tabular}{|c|c|c|c|c|}
\hline \multirow{2}{*}{ No } & \multirow{2}{*}{$\begin{array}{l}\text { Tipe } \\
\text { KPH }\end{array}$} & \multirow[t]{2}{*}{ Kebutuhan SDM seharusnya } & \multicolumn{2}{|c|}{ Ketersediaan SDM saat ini } \\
\hline & & & KPHL Batutegi & KPHL Kota agung Utara \\
\hline 1 & A & $\begin{array}{l}138 \text { orang terdiri dari } \\
-\quad \text { Pejabat struktural } 4 \text { orang } \\
\text { - Jabatan fungsional umum } 35 \\
\text { orang } \\
\text { - Jabatan fungsional tertentu } \\
\text { 99 orang }\end{array}$ & - & $\begin{array}{l}23 \text { orang terdiri dari } \\
-\quad \text { Pejabat struktural } 4 \text { orang } \\
-\quad \text { Jabatan fungsional umum } \\
19 \text { orang }\end{array}$ \\
\hline 2 & B & $\begin{array}{l}77 \text { orang terdiri dari } \\
\text { - } \quad \text { Pejabat struktural } 4 \text { orang } \\
\text { - Jabatan fungsional umum } 20 \\
\text { orang } \\
\text { - Jabatan fungsional tertentu } 53 \\
\text { orang }\end{array}$ & $\begin{array}{l}20 \text { orang terdiri dari } \\
\text { - Pejabat struktural } 4 \text { orang } \\
\text { - Jabatan fungsional umum } \\
16 \text { orang }\end{array}$ & - \\
\hline 3 & $\mathrm{C}$ & $\begin{array}{l}34 \text { orang terdiri dari } \\
\text { - } \quad \text { Pejabat struktural } 4 \text { orang } \\
\text { - Jabatan fungsional umum } 13 \\
\text { orang } \\
\text { - Jabatan fungsional tertentu } 17 \\
\text { orang }\end{array}$ & - & - \\
\hline
\end{tabular}

Sumber: Fathoni, 2014

Berdasarkan tabel diatas SDM di KPHL Batutegi dan Kota Agung Utara memliki ketersediaan SDM yang jumlahnya belum ideal dibandingkan jumlah SDM seharusnya. Untuk KPHL Batutegi memiliki 4 pejabat struktural dan 16 jabatan fungsional umum, sehingga jumlah SDM yang perlu ditingkatkan yaitu 4 jabatan fungsional umum dan 53 orang untuk jabatan fungsional tertentu. Sedangkan untuk KPHL Kota Agung Utara memiliki 4 pejabat struktural dan 19 jabatan fungsional umum, sehingga SDM yang diperlukan 16 jabatan fungsional umum dan 99 orang untuk jabatan fungsional tertentu.

\section{Kecukupan Jumlah Sumberdaya Manusia dan Tingkat Pendidikan}

Jumlah SDM pada suatu KPHL berpengaruh terhadap pengelolaan teknis kawasan hutan lindung, selain hal tersebut tingkat pendidikan para pegawai juga berpengaruh terhadap potensi sumberdaya manusia, hal ini dapat dilihat pada Tabel 8.

Tabel 8. Jumlah SDM menurut tingkat pendidikan.

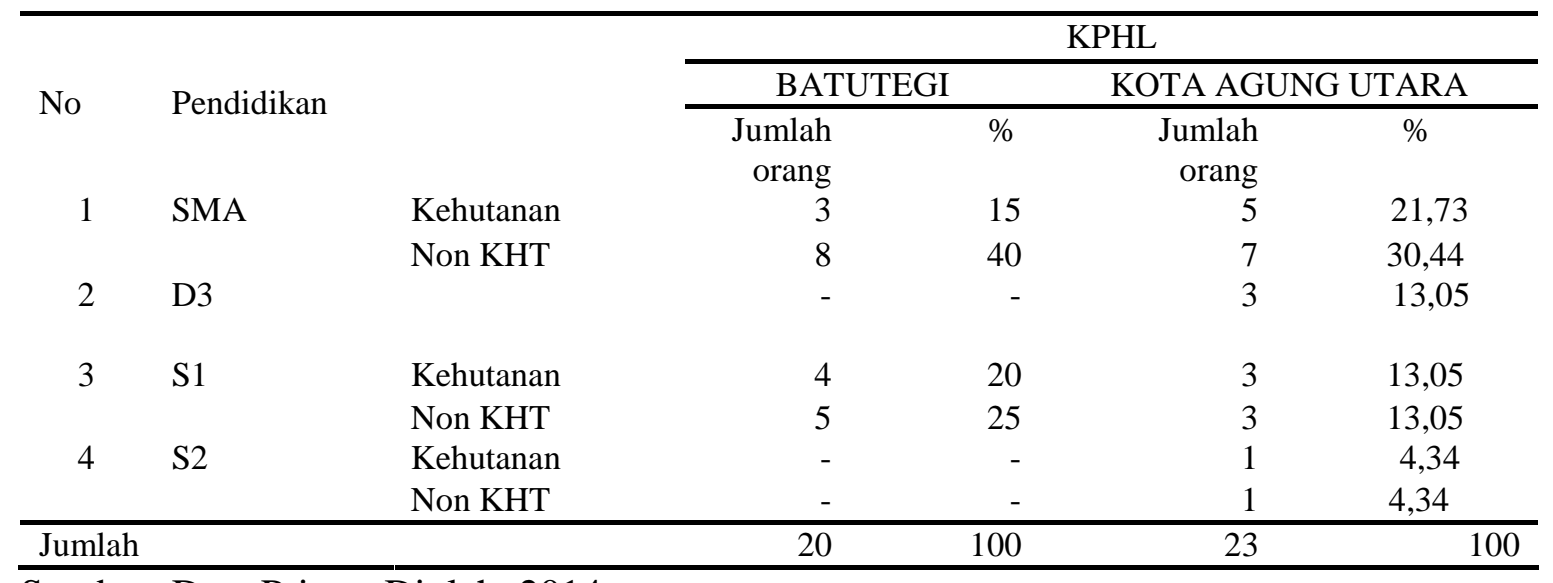

Sumber: Data Primer Diolah, 2014 
Berdasarkan Tabel 8. tingkat pendidikan pegawai di KPHL Batutegi pendidikan paling tinggi yang dimiliki SDM yakni S1, dari seluruh SDM di KPHL Batutegi hanya 35\% yang berlatar belakang pendidikan bidang kehutanan sedangkan untuk SDM di KPHL Kota Agung Utara pendidikan yang paling tinggi yakni Strata 2, serta memiliki 39,12\% SDM yang pendidikannya berlatar belakang kehutanan. Kedua KPHL memiliki SDM dengan tingkat pendidikan yang beragam hal ini sesuai dengan pendapat Triani (2009) bahwa tingkat pendidikan yang beragam akan menyebabkan tingkat pengetahuan yang berbeda, sehingga dalam menanggapi sesuatu hal relatif berbeda. Menurut Edi (2013), pendidikan merupakan faktor yang mencerminkan kemampuan seseorang untuk dapat menyelesaikan suatu pekerjaan. Tingkat pendidikan tertentu para seorang pegawai akan melatarbelakangi pengetahuan tertentu sehingga mampu serta cakap untuk melaksanakan tugasnya.

Berdasarkan Peraturan Daerah Kabupaten Tanggamus No 21 tahun 2011, untuk KPHL Kota Agung Utara termasuk tipe A karena merupakan Satuan Kerja Perangkat Daerah (SKPD) yang berada di bawah dan bertanggung jawab kepada Kepala Daerah melalui Sekretaris Daerah Kabupaten. Jika dilihat dari struktur organisasi yang ada sekarang KPHL Kota Agung Utara dalam pemetaan sumberdaya manusia sudah memenuhi susunan struktur organisai berdasarkan Peraturan dalam Negeri yakni terdiri dari kepala KPHL, sub bagian tata usaha, seksi perencanaan hutan dan seksi tata hutan dan pelindungan hutan serta kelompok jabatan fungsional. Sedangkan untuk KPHL Batutegi berdasarkan Peraturan Gubernur Lampung Nomor 27 tahun 2010 termasuk tipe B karena masih berupa Unit Pelaksanaan Teknis Daerah jika dilihat dari syarat kecukupan sumberdaya manusia untuk memenhui jabatan berdasarkan Departemen Kehutanan, KPHL Batutegi sudah memiliki kepala KPHL, sub bagian tata usaha, serta kelompok jabatan fungsional bahkan saat pengambilan data kuesioner pada KPHL Batutegi sudah memiliki seksi bina hutan. Menurut Kusdi (2009) struktur organisasi pada hakikatnya adalah suatu cara untuk menata unsur-unsur dalam organisasi dengan sebaik-baiknya, demi mencapai berbagai tujuan yang telah ditetapkan.

\section{Pengembangan Kesatuan Pengelolaan Hutan Lindung (KPHL)}

\section{Kondisi optimal KPHL}

Kondisi optimal KPHL dapat dilihat dari jumlah pegawai dan tingkat pendidikan formal pegawai, selain pendidikan formal pegawai juga mendapatkan pendidikan non formal (pelatihan), hal ini dapat berpengaruh dalam upaya pengembangan KPHL. Berdasarkan Tabel 4, pegawai masing-masing KPHL memiliki pendidikan non formal yang beragam hal. Menurut Husein (2005) pelatihan adalah program yang bertujuan untuk memperbaiki keterampilan dan teknik pelaksana kerja pegawai untuk kebutuhan sekarang, peningkatan dalam keilmuan, pengetahuan, kemampuan, sikap dan kepribadian untuk menyiapkan karyawan memangku tugas di masa yang akan datang. Penelitian yang dilakukan oleh Nyoman (2013), Djuadi dan Harahap (2007) serta Lubis (2008), berhasil menemukan bahwa diklat merupakan faktor yang berpengaruh positif dan signifikan terhadap kinerja karyawan. Oleh karena itu SDM pada KPHL Batutegi dan KPHL Kota Agung Utara harus mengikuti Diklat sesuai dengan jabatannya atau mengadakan Diklat untuk para pegawainya agar lebih optimal dalam upaya pengembangan KPHL.

Berdasarkan uraian diatas menunjukan bahwa walaupun pegawai KPHL telah mengikuti pelatihan yang sama namun memiliki tingkat kepotensian yang berbeda (Gambar 3 dan 4). Hal ini diduga disebabkan oleh tingkat pendidikan formal, untuk itu pegawai KPHL diharapkan untuk melanjutkan ke jenjang pendidikan yang lebih tinggi dan sebidang. 
Tabel 9. Pelatihan yang pernah diikuti SDM di KPHL Batutegi dan Kota Agung Utara.

\begin{tabular}{llcc}
\hline \multirow{2}{*}{ No } & Pelatihan & \multicolumn{2}{c}{ KPHL } \\
\cline { 3 - 4 } & & Batu Tegi & Kota Agung Utara \\
\hline 1. & GIS & $\checkmark$ & $\checkmark$ \\
2. & Analisis Perencanaan kehutanan & $\checkmark$ & $\checkmark$ \\
3. & Workshop on rapid carbon & $\checkmark$ & $\checkmark$ \\
4. & Diklat calon KKPH & $\checkmark$ & $\checkmark$ \\
5. & Pengenalan Satwa & $\checkmark$ & $\checkmark$ \\
6. & Diklat Basarhut & $\checkmark$ & \\
\hline
\end{tabular}

Sumber: Data primer, 2014

Setelah mengikuti pelatihan, pada umumnya SDM dari kedua KPHL tidak mengimplementasikan ilmu yang telah diperoleh dari pelatihan.

2. Persepsi Masyarakat dan Lembaga Swadya Masyarakat Tentang Dibentuknya KHPL

a. Persepsi Masyarakat Sekitar Hutan Lindung

Pengembangan KPHL tidak hanya didukung oleh potensi SDM, namun juga keberadaan masyarakat yang berbatasan langsung dengan wilayah KPHL tersebut. Untuk itu perlu diketahui persepsi masyarakat tentang dibentuknya KPHL. Masyarakat sekitar hutan lindung memiliki persepsi bemacam-macam dalam pembentukan kawasan KPHL hal ini dapat dilihat pada tabel 10, 91\% masyarakat sekitar KPHL Batutegi setuju dengan keberadaan kawasan KPHL dan 9\% kurang setuju, sedangkan masyarakat sekitar KPHL Kota Agung Utara 100\% setuju dengan keberadaan KPHL.

Tabel 10. Persepsi masyarakat sekitar KPHL terhadap dibentuknya KPHL (\%).

\begin{tabular}{ccrrrr}
\hline \multirow{2}{*}{ No } & \multirow{2}{*}{ KPHL } & \multicolumn{3}{c}{ Persepsi } \\
\cline { 3 - 6 } & & \multicolumn{2}{c}{ Setuju } & \multicolumn{2}{c}{ Kurang Setuju } \\
\cline { 3 - 6 } & & Sangat Setuju & Setuju & Kurang Setuju & Tidak Setuju \\
\hline 1. & Batutegi & 55 & 36 & 9 & - \\
2. & Kota Agung Utara & 80 & 20 & - & - \\
\hline
\end{tabular}

Sumber: Data Primer, 2014

Persepsi masyarakat yang baik disebabkan oleh adanya penyuluhan dan pendampingan oleh pihak KPHL untuk masyarakat sekitar hutan dalam pengelolaan hutan. Hal ini sesuai dengan penelitian Vitayala (2007), penyuluhan sebagai proses pembelajaran (pendidikan nonformal) yang ditujukan untuk petani dan keluarganya memiliki peran penting dalam pencapaian tujuan pembangunan bidang pertanian dan kehutanan. Penyuluh sebagai komunikator pembangunan diharapkan dapat bermain multiperan, sebagai guru, pembimbing, penasehat, penyampai informasi dan mitrapetani. Masyarakat sekitar KPHL Kota Agung Utara selain mendapat penyuluhan mereka juga mengikuti program sekolah petani, mereka dibina dan diajarkan cara pengelolaan hutan lindung yang baik dari cara penanaman pohon yang baik sampai pengelolaan hasil hutan non kayu. Selain itu, masyarakat berpendapat dengan dibentuknya kesatuan pengelolaan dapat mempermudah jalur koordinasi dengan para 
pihak terkait dalam pengelolaan kawasan serta memudahkan masyarakat jika ingin berkoordinasi dengan pemerintah pusat.

\section{b. Persepsi Lembaga Swadaya Masyarakat (LSM) Terhadap Terbentuknya KPHL}

Lembaga swadaya masyarakat yang bekerjasama dengan KPHL setuju dengan dibentuknya kesatuan pengelolaan hutan hal ini dapat dilihat pada Tabel 11. sebesar 100\% sangat setuju untuk LSM yang bekerjasama dengan KPHL Kota Agung Utara dan untuk LSM KPHL Batutegi sebesar 100\% hal yang mendasari mereka sangat setuju karena pelestarian hutan harus dimulai dari tingkat tapak sehingga harus dibentuk kesatuan pengelolaan hutan untuk melestarikan hutan ditingkat tapak dan KPH berbeda dengan dinas yang ada di Provinsi/Kabupaten/Kota yang menangani kehutanan secara administrasi sehinggan apalabila KPH belum dibentuk dikhawatirkan tidak ada yang menangani fungsi pengelolaan ditingkat tapak (lapangan). Peran LSM dalam membantu pengembangan kawasan KPHL sangat dibutuhkan baik memberi masukan kepada pihak KPHL dan mendampingi masyarakat sekitar hutan dalam pengelolaan wilayah hutan lindung. Seperti yang dikemukakan oleh Sajogyo (1990), bahwa LSM memiliki peranan yang cukup penting sebagai pelaku dalam pembangunan perdesaan, disamping lembaga-lembaga yang dibina langsung oleh pemerintah.

Tabel 11. Persepsi LSM terhadap dibentuknya KPHL (\%).

\begin{tabular}{llrrrr}
\hline \multirow{2}{*}{ No } & \multirow{2}{*}{ KPHL } & \multicolumn{3}{c}{ Persepsi } \\
\cline { 3 - 6 } & & 100 & Setuju & \multicolumn{2}{c}{ Kurang Setuju } \\
\cline { 3 - 6 } & & Sangat Setuju & Setuju & Kurang Setuju & Tidak Setuju \\
\hline 1. & Batutegi & 89 & 11 & - & - \\
2. & Kota Agung Utara & & - & - \\
\hline
\end{tabular}

Sumber: Data primer, 2014

Seperti halnya menurut Nurmelati (2011) Keberadaan LSM sebagai salah satu lembaga di luar pemerintah, selama ini mampu menjembatani dan mengakomodir serta membantu memecahkan masalah yang berkaitan dengan kebutuhan masyarakat.

\section{Kesimpulan}

\section{KESIMPULAN}

Berdasarkan hasil penelitian dapat disimpulkan sebagai berikut :

1. Sumberdaya manusia di KPHL Batutegi yang berkualitas sebesar 39\% dan kurang berkualitas sebesar $61 \%$ dan KPHL Kota Agung Utara yang berkualitas $42 \%$ dan kurang berkualitas sebesar $58 \%$.

2. Upaya peningkatan kuantitas dan kualitas SDM yaitu mengoptimalkan jumlah pegawai sesuai dengan kebutuhan sesuai pernyataan fathoni (2014) yakni untuk KPHL Batutegi 4 SDM jabatan fungsional umum dan 53 SDM jabatan fungsional tertentu, sedangkan untuk KPHL Kota agung Utara 16 SDM jabatan fungsional umum dan 99 SDM untuk jabatan fungsional tertentu. Serta memperbanyak kegiatan pelatihan bidang kehutanan.

\section{Saran}

Pada KPHL Batutegi persentase kualitas SDM paling rendah dalam perencanaan hutan yaitu bidang penatagunaan lahan, serta dalam pengelolaan DAS dan perhutanan sosial persentase nilai yang rendah yakni bidang aneka usaha kehutanan dan perbenihan sosial. Sedangkan untuk KPHL Kota Agung Utara persentase kualitas SDM nilai paling rendah 
dalam perencanaan hutan yaitu bidang penatagunaan lahan, serta pada pengelolaan DAS dan perhutanan sosial nilai paling rendah di bidang aneka usaha kehutanan. Dengan demikian masing-masing KPHL dapat meningkatkan kualitas SDM, baik pendidikan formal maupun nonformal dalam bidang yang berpersentase rendah.

\section{DAFTAR PUSTAKA}

Abdul, M. 2008. Sumberdaya Manusia. Buku. Mandar Maju. Bandung. 72 p.

Djuadi, D dan S. Harahap. 2007. Pengaruh pendidikan dan latihan (diklat) dan disiplin pegawai terhadap kinerja pegawai kantor departemen agama kota medan. Jurnal Ekonomi Bisnis Indonesia. 2(7): 46-60.

Edi. 2013. Pengaruh pendidikan dan pelatihan terhadap kinerja pegawai (studi ada badan kepegawaian daerah kota malang. Jurnal Administrasi Publik. 2(1):116-121.

Elfina. 2007. Pengaruh program pendidikan dan pelatihan terhadap prestasi kerja karyawan pada pt. inti (persero) bandung. Skripsi. Universitas Widyatama. 135 p.

Fathoni, T. 2014. Operasionalisasi Kesatuan Pengelolaan Hutan (KPH): Langkah Awal Menuju Kemandirian. Buku. Kanisius. Yogyakarta. 38 p.

Hasan, I. 2006. Analasisi Data Penelitian. Buku. Andi Offset. Yogyakarta. 150 p.

Husein, U. 2005. Evaluasi Kinerja Perusahaan. Buku. Gramedia Pustaka Utama. Jakarta. $89 \mathrm{p}$.

Kusdi. 2009. Teori Organisasi dan Administrasi. Buku. Salemba Humanika. Jakarta. 112 p.

Lestari. S, S. Nugroho, D. Setiawan, M. Soraya, M. Rachman. 2012. Data dan Informasi Kesatuan Pengelolaan Hutan. Direktorat Wilayah Pengelolaan dan Penyiapan Areal Pemanfaatan Kawasan Hutan, Ditjen Planologi Kehutanan. Buku. Jakarta. 245 p.

Lubis, K. 2008. Pengaruh pelatihan dan motivasi kerja terhadap kinerja karyawan pt. perkebunan nusantara iv (persero)medan. Tesis. Sekolah Pascasarjana Universitas Sumatera Utara Medan. 84 p.

Nyoman, J. 2013. Pengaruh kepemimpinan, diklat, dan disiplin kerja terhadap kineja karyawan pdam tirta mangutama kabupaten bandung. Jurnal Managemen, Strategi Bisnis, dan kewirausahaan. 2 (7):126-134.

Nurmelati. 2011. Peran lsm dalam mendukung kebijakan pengarusutamaan gender pada kegiatan pengelolaan sumberdaya alam. Jurnal Agribisnis Perdesaan. 1(2):158-165.

Sudjarwo dan Basrowi. 2009. Manajemen Penelitian Sosial. Buku. Mandar Maju. Bandung. $356 \mathrm{p}$.

Suratno. Konsep Kemampuan Sumberdaya Manusia. 2012. 11 Juni 2015. sulut.kemenag.go.id/file/file/.../aunw1341283316.pdf.

Sajogyo, P. Partisipasi LSM dan LPSM dalam Pembangunan di Pedesaan Jawa Barat. Pusat Studi Pembangunan Lembaga Penelitian IPB. 1990. 20 Januari 2015. https://www.academia.edu/5507801/012_07-melati_Peran-LSM.

Triani, A. 2009. Analisis willingness to accept masyarakat terhadap pembayaran jasa lingkungan das cidanau. Skripsi. Fakultas Ekonomi dan Manajemen IPB. Bogor. $121 \mathrm{p}$.

Undang-Undang RI nomor 41 tahun 1999. Tentang Kehutanan 2013. 15 Juli 2013. http://Prokum.Esdm.Go.Id/Uu/1999/Uu-41-1999.Pdf.

Vitayala, AS. 2007. Motivasi, kepuasan kerja dan produktivitas penyuluh pertanian lapangan:kasus kabupaten sukabumi. Jurnal Penyuluhan. 3(7):90—99.

Widianti, E. Pengetahuan Pasien Mengenai Gangguan Psikosomatik dan Pencegahannya di $\begin{array}{lllll}\text { Puskesmas Tarogong Garut. } 2007 . & 13 & \text { September } 2014 .\end{array}$ http://dokumen.tips/documents/pengetahuan-pasien-mengenai-gangguanpsikosomatik-dan-pencegahannya-di-puskesmas-tarogong-garut-55b83fe $5 \mathrm{~d} 4160 \mathrm{html}$. 